\title{
MÉTODOS DE AVALIAÇÃO DA INFLUÊNCIA E CONTRIBUIÇÃO DAS PLANTAS SOBRE A ESTABILIDADE DE TALUDES
}

\author{
Evaluation methods of plants influence and contribution on slope stability
}

\author{
Charles Rodrigo Belmonte Maffra ${ }^{1 *}$; Moacir Tuzzin de Moraes ${ }^{2}$; Rita dos Santos Sousa ${ }^{3}$; Fabrício Jaques Sutili; \\ Rinaldo José Barbosa Pinheiro ${ }^{5}$ José Mario Doleys Soares ${ }^{6}$ \\ ${ }^{1}$ Doutorando em Engenharia Florestal; Universidade Federal de Santa Maria; e-mail: charles.maffra@gmail.com \\ *Autor para correspondência \\ 2 Pós-doutorando; Centro de Energia Nuclear na Agricultura; Universidade de São Paulo; e-mail: \\ moacirtuzzindemoraes@gmail.com \\ ${ }^{3}$ Doutoranda em Engenharia Florestal; Universidade Federal de Santa Maria; e-mail: ritasousa.ufsm@gmail.com \\ ${ }^{4}$ Professor; Departamento de Ciências Florestais; Universidade Federal de Santa Maria; e-mail: fjsutili@gmail.com \\ 5 Professor; Departamento de Transportes; Universidade Federal de Santa Maria; e-mail: rinaldo@ufsm.br \\ ${ }^{6}$ Professor; Departamento de Estruturas e Construção Civil; Universidade Federal de Santa Maria; e-mail: jmario337@gmail.com
}

Artigo enviado em 19/05/2017, aceito em 25/09/2017 e publicado em 20/12/2017.

Resumo: O reforço e estabilização de solos por plantas são facilmente observados na natureza. Entretanto, o uso de plantas (e suas raízes) em obras de Engenharia Natural requer conhecimentos e medições de seus efeitos na estabilidade do solo. O objetivo desta revisão foi abordar e discutir conceitualmente os métodos utilizados para avaliação da influência das raízes sobre a melhoria da resistência mecânica do solo e sua inclusão na análise de estabilidade de taludes. A estabilização de taludes, seja pela redução da erodibilidade ou ancoramento do solo em profundidade, está diretamente associada à arquitetura e à densidade de comprimento radicular das espécies e do tipo de planta utilizada (gramínea, arbusto ou árvore). As informações compiladas mostram-se úteis aos trabalhos que envolvem o uso de plantas em dimensionamentos geotécnicos, seja para a contenção de processos erosivos ou para a estabilização superficial de massas de solo. O reforço mecânico do solo devido à presença de raízes tem papel de grande importância na estabilidade de taludes, no entanto, técnicas de avaliação da interação solo-raízes ainda devem ser aprimoradas para condições de campo.

Palavras-Chave - Engenharia Natural, interação solo-raízes, reforço do solo, sistema radicular, fator de segurança.

Abstract: Soil reinforcement and stabilization by plants are easily observed in nature. However, the use of plants (and its roots) in Soil Bioengineering works requires knowledge and measurements of its effects on soil stability. The aim of this study was to approach and conceptual discuss the methods used to evaluate the influence of roots on soil mechanical resistance improvement and its inclusion in slope stability analysis. The slope stabilization, either by decreasing soil erodibility or increasing soil anchorage, is directly associated with root length density and root architecture, both of which depend on the species and type of plant used (grass, shrub or tree). This information can be useful in geotechnical designs, especially in erosion control and shallow mass stabilization. Soil reinforcement by roots plays an important role in slope stability; however, the techniques of soil-root interaction assessment should be improved to field conditions.

Keywords - Soil Bioengineering, soil-root interaction, soil reinforcement, root system, factor of safety. 


\section{INTRODUÇÃO}

O importante papel desempenhado pelas plantas na estabilização de margens de cursos de água e encostas há muito tempo é aceito e reconhecido (WU, 1995). É por meio da ação integrada entre parte aérea e sistema radicular que as plantas conferem ao solo maior competência para suportar as forças cisalhantes que atuam sobre um talude (GYSSELS et al., 2005). Essa contribuição é fundamental para o controle de processos de dinâmica superficial, como é o caso das erosões hídrica ou eólica (processo de transporte de massa) e também dos movimentos de massa (processos gravitacionais) (VAN BEEK et al., 2008).

A avaliação das propriedades de resistência do sistema solo-raiz depende da análise das características físicas de ambos. Para os solos existem métodos padronizados de avaliação dos parâmetros de resistência (coesão e ângulo de atrito interno), obtidos normalmente por testes de resistência ao cisalhamento direto ou triaxial (LAMBE; WHITMAN, 1969). Para as plantas são considerados principalmente os valores de resistência à tração (DE BAETS et al., 2008), obtidos por métodos ainda não padronizados e que envolvem uma série de simplificações. Por essas razões, considerar a interação entre solo e raízes em análises de estabilidade de taludes, além de determinações realizadas in situ, pode envolver o uso de modelos simplificados e estimativas.

A avaliação simplificada dos efeitos das raízes sobre o reforço dos solos é uma necessidade prática à difusão do uso de espécies vegetais especificadas para esta finalidade. O comportamento dinâmico e errático dos sistemas radiculares dentro do solo impõe uma série de incertezas e limitações matemáticas, que podem levar à obtenção de informações apenas aproximativas do reforço resultante da interação entre esses dois elementos. Isso, no entanto, não significa uma redução na importância e utilidade dos valores obtidos por pedofunções, sobretudo se os mesmos forem empregados cautelosamente.

Temas relacionados ao desempenho das plantas na estabilização de massas e controle de processos erosivos, ainda são relativamente pouco estudados para uso em abordagens de Recuperação de Áreas Degradadas e Engenharia Natural (GRAY; SOTIR, 1996; GYSSELS et al., 2005; MAFFRA, 2014). Procedimentos e métodos padronizados para a realização de testes de cisalhamento, arranquio ou tração, que são os mais empregados, são igualmente escassos ou inexistentes. Da mesma forma, são insuficientes as informações relativas à modificação das propriedades de resistência das raízes em diferentes espécies, densidades de plantio, tempo e características do ambiente de desenvolvimento.

A ausência de informações quantitativas, assim como o desconhecimento de métodos para avaliar e incluir os efeitos mecânicos das raízes sobre o solo, impedem que as plantas sejam empregadas de modo mais eficiente na proteção e estabilização de taludes.

Assim como qualquer outro material de engenharia, as plantas também precisam ter o desempenho medido e avaliado de modo analítico. Para isso, é fundamental que o entendimento sobre o assunto seja aprimorado em escala de avaliações de campo.

O presente trabalho teve por objetivo abordar e discutir conceitualmente os métodos utilizados para avaliação da influência das raízes sobre a melhoria da resistência mecânica do solo e a inclusão dos efeitos desses elementos vivos na análise de estabilidade de taludes.

\section{AS PLANTAS E A RESISTÊNCIA DO SOLO \\ $O$ papel da vegetação sobre a estabilidade e proteção de taludes}

A influência da vegetação sobre a estabilidade e proteção de taludes ocorre de duas formas: por meio dos efeitos hidrológicos e dos efeitos mecânicos (COPPIN; RICHARDS, 2007). Os efeitos hidrológicos envolvem a parte aérea e radicular das plantas e proporcionam interceptação de água da chuva, diminuição da velocidade da água durante o escoamento superficial, alterações nas taxas de infiltração e de evaporação de água no solo, e absorção de água pelas raízes com consequente transpiração (GRAY; SOTIR, 1996) (Figura 1). Já os efeitos mecânicos de agregação, ancoramento e de resistência ao cisalhamento do solo são resultados da presença de raízes (COPPIN; RICHARDS, 2007; MORGAN; RICKSON, 1995).

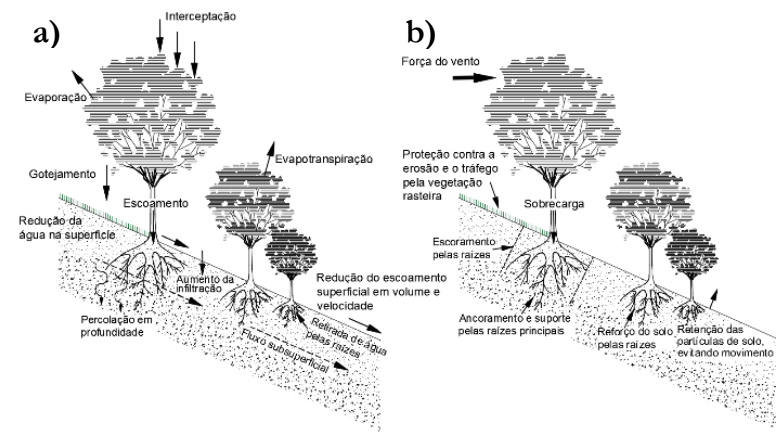

Figura 1. Efeitos hidrológicos (a) e mecânicos (b) da vegetação no solo em taludes (Adaptado de COPPIN e RICHARDS, 2007).

De modo geral, efeitos hidrológicos e mecânicos contribuem para a redução das solicitações na superfície do solo com aumento da resistência de camadas superficiais e subsuperficiais.

As plantas podem desempenhar efeitos positivos e negativos na estabilidade de taludes. Como efeitos positivos, pode ser destacado o reforço mecânico do solo pelas raízes (STOKES et al. 2008), a redução do conteúdo de água do solo pela absorção de água pelas raízes (MORGAN; RICKSON, 1995) e ação de ancoramento do solo pelo crescimento das raízes (STYCZEN; MORGAN, 1995). Como efeitos negativos são destacados a sobrecarga, efeito de cunha das raízes e o tombamento pela ação do vento (GRAY; LEISER, 1982). Nos taludes, os efeitos negativos são normalmente 
desenvolvidos pela presença de árvores de grande porte, alocadas em posições inadequadas (centro e topo do talude) (DURLO; SUTILI, 2014). Esse é um dos motivos pelo qual se preconiza o uso de espécies arbustivas na estabilização de taludes.

A contribuição mais efetiva das plantas para a estabilidade de uma massa de solo se dá por meio do reforço mecânico proporcionado pelas raízes (GRAY; SOTIR, 1996). Diversos estudos desenvolvidos in situ (LAWRENCE; RICKSON; CLARK, 1996; MICKOVSKI; VAN BEEK, 2009; VEYLON et al., 2015; WALDRON, 1977; WU; MCKINNELL; SWANSTON, 1979) e em laboratório (OPERSTEIN; FRYDMAN, 2000; GHESTEM et al., 2014) indicam que o reforço do solo propiciado por pequenas quantidades de raízes pode conferir grande aumento de sua resistência ao cisalhamento.

\section{Propriedades mecânicas das raízes na resistência do solo}

O uso de plantas em obras de estabilização de solos tem efeitos reconhecidamente positivos em sua fixação (OPERSTEIN; FRYDMAN, 2000). Esse efeito, que resulta majoritariamente do reforço e ancoramento proporcionado pelas raízes, é governado por fatores como arquitetura do sistema radicular, resistência das raízes e interação solo-raízes (REUBENS et al., 2007).

\section{Morfologia do sistema radicular}

A morfologia ou arquitetura do sistema radicular é complexa e apresenta elevada variação entre diferentes espécies, tipos de solo e condições ambientais (COUTTS, 1983). Também apresenta grande sensibilidade à variação de fatores físicos como aeração, temperatura, disponibilidade hídrica e resistência mecânica à penetração (LETEY, 1985).

Quando não são limitadas pelas condições químicas, físicas ou de profundidade do perfil dos solos, as plantas herbáceas, arbustivas e arbóreas conseguem expressar suas feições morfológicas ou de arquitetura radicular (NORRIS et al., 2008). Os termos lateral, pivotante e secundária são comumente utilizados para descrever as diferentes raízes de uma planta lenhosa (Figura 2).

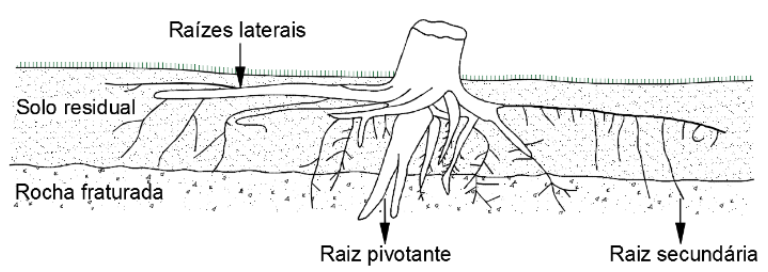

Figura 2. Principais componentes do sistema radicular de uma planta lenhosa, incluindo raízes laterais, pivotantes e secundárias (Adaptado de GRAY e SOTIR, 1996).

O aspecto geral ou morfologia do sistema radicular também pode ser categorizado. Três formas distintas são reconhecidas: plate ou sinker (secundárias), com amplas raízes laterais e pequenas raízes verticais; heart (coração), com muitas raízes verticais e horizontais; e tap (aprumada), com raiz central (pivotante) e raízes laterais amplas e de proporções semelhantes (Figura 3a). Variantes dessas formas também podem ocorrer, uma vez que a morfologia é controlada pela genética, condições de solo e forma de propagação das plantas (GRAY; SOTIR, 1996). A representação integral dessas formas pode ser bastante complexa, por isso existem representações aproximativas de suas formas geométricas (Figura 3b).

$\mathrm{Na}$ estabilidade de taludes, o desenvolvimento de uma arquitetura radicular específica pode determinar a maior ou menor contribuição na resistência do solo (COUTTS, 1983). Sistemas radiculares fortes e verticais, que penetram as superfícies potenciais de ruptura ou de cisalhamento dos solos, têm maior potencial para aumentar a estabilidade de taludes contra deslizamentos (STYCZEN; MORGAN, 1995), funcionando como um sistema de ancoragem que interliga diferentes camadas de solo. Da mesma forma, sistemas radiculares com alta densidade de raízes finas podem ser mais efetivos, no aumento da resistência ao cisalhamento do solo, do que aqueles constituídos por poucas raízes de diâmetros maiores (GRAY; SOTIR, 1996; NILAWEERA; NUTALAYA, 1999).
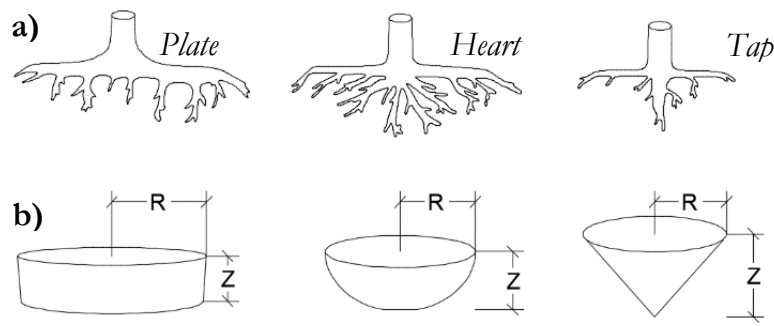

Figura 3. Representação esquemática da forma natural de sistemas radiculares do tipo plate, heart e tap (STOKES; MATTHECK, 1996) (a); e aproximações geométricas dos sistemas radiculares (KOKUTSE et al, 2006) (b). $R$, raio médio do sistema radicular; $Z$, profundidade efetiva do sistema radicular.

Além disso, por terem maior área superficial específica, sistemas radiculares compostos por raízes finas são mais eficientes no confinamento do solo, o que constitui um mecanismo útil para minimizar perdas por erosão superficial (MORGAN; RICKSON, 1995; COPPIN; RICHARDS, 2007; ALI; OSMAN, 2008). De modo geral, as raízes têm sido classificadas de acordo com o diâmetro em muito finas $(<0,5 \mathrm{~mm})$, finas $(0,5-2$ $\mathrm{mm})$, pequenas $(2-5 \mathrm{~mm})$, médias $(5-10 \mathrm{~mm})$ e muito grandes ou grossas (>20 mm) (BÖHM, 1979). É comum que o sistema radicular de espécies lenhosas, principalmente em arbóreas e arbustivas, apresente tanto raízes grossas quanto raízes finas.

A capacidade das raízes lenhosas em estabilizar o solo também é fortemente influenciada pela sua simetria. Normalmente a estabilidade é melhorada se a distribuição das raízes for simétrica. No entanto, em taludes, as raízes tendem a ter uma distribuição 
assimétrica no entorno da planta (NICOLL et al., 2006). No início do desenvolvimento das plantas essa pode ser uma resposta à maior disponibilidade de nutrientes e água. A longo prazo, o desenvolvimento assimétrico pode ser uma resposta ao estresse mecânico, que modifica o número e/ou espessura das raízes na direção das tensões sofridas (STOKES et al., 2008). As tensões solicitantes mais comuns podem ser provocadas pela força do vento, energia do fluxo de água e movimentação de massas de solo. Nesse caso, para plantas em taludes, a quantidade de raízes, assim como o seu espessamento, tende a ocorrer de maneira mais pronunciada na direção do declive (sentido topo base do talude) (DANJON; KHUDER; STOKES, 2013).

\section{Resistência das raízes}

A resistência à tração das raízes é um "fator chave" no entendimento e predição da estabilização dos solos (LOADES et al., 2013a). A resistência à tração é a máxima força aplicada por unidade de área para provocar a ruptura de um determinado material $\left(\sigma_{\text {rup }}=F_{\text {máx }} /\right.$ Área $)$. Nas plantas, esse teste pode ser realizado para raízes individuais (GENET et al., 2005), para um conjunto de raízes (GHESTEM et al., 2014), em raízes com diferentes idades (LOADES et al., 2015), ou até mesmo para uma ou mais plantas inteiras (LOADES et al., 2010). Esse tipo de ensaio fornece também a relação da resistência à tração com a deformação sofrida pelo material até o ponto de ruptura (LOADES et al., 2013a), o que possibilita o cálculo do módulo de elasticidade, usado para determinar deformações elásticas e plásticas no material. A medida padrão utilizada é a relação da força por área que é Pascal $\left(\mathrm{N} \mathrm{m}^{-2}\right)$ ou suas variações (LOADES et al., 2013b), mas em alguns estudos os valores são apresentados apenas em termos de força (VERGANI et al., 2014), o que dificulta o uso destes valores para análises de contribuição das raízes à resistência dos solos.

A resistência das raízes varia muito, não somente inter e intraespécies, mas também dentro de um mesmo sistema radicular (NORRIS et al., 2008). As variações dependem principalmente da espécie (genética) (STOKES et al., 2008), ambiente de desenvolvimento (SCHIECHTL; STERN, 1996), estação do ano, diâmetro da raiz (GRAY; SOTIR, 1996), orientação (GHESTEM et al., 2014) e constituição (teores de celulose e lignina) (ZHANG; CHEN; JIANG, 2014).

As raízes contribuem normalmente com incrementos na resistência à tração na faixa de 8 a $80 \mathrm{MPa}$ (NILAWEERA; NUTALAYA, 1999). Os valores máximos, dependendo da espécie, muitas vezes podem ultrapassar os $300 \mathrm{MPa}$ (BISCHETTI et al., 2005). Dentro desses limites, raízes de arbustos e de árvores têm apresentado valores semelhantes (GRAY; SOTIR, 1996).

As raízes mais finas contribuem mais do que raízes grossas, no reforço e aumento da resistência ao cisalhamento do solo (GRAY; SOTIR, 1996), incrementando a resistência ao arranquio (OPSTEIN; FRYDMAN, 2000), o que ocorre devido ao aumento exponencial da área superficial em função da redução do diâmetro das raízes (ALI; OSMAN, 2008). Entretanto, a maior resistência à tração das raízes finas não implica necessariamente em maior reforço do solo (LOADES et al., 2013a). A relação entre resistência à tração e diâmetro de raízes é expressa na forma de uma equação logarítmica simples (Equação 1) (GRAY; SOTIR, 1996).

$$
\mathrm{T}_{\mathrm{r}}=\mathrm{n} \cdot \mathrm{D}^{\mathrm{m}}
$$

Onde: $\mathrm{T}_{\mathrm{r}}$ é a resistência à tração $(\mathrm{MPa}) ; \mathrm{D}$ é o diâmetro da raiz; n e m são os parâmetros da equação.

Diversos estudos indicam que a relação entre resistência à tração e diâmetro de raízes apresenta uma tendência que é descrita por uma equação de potência negativa (Figura 4) (BISCHETTI et al., 2005; GENET et al., 2005; MATTIA; BISCHETTI; GENTILE, 2005). A redução da resistência à tração conforme as raízes aumentam em diâmetro (Figura 4) pode ser explicada pela sua composição química primária, uma vez que raízes finas apresentam maiores teores de celulose e menores teores de lignina (ZHANG; CHEN; JIANG, 2014).

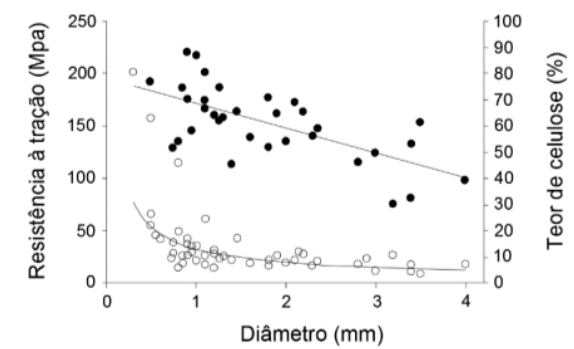

Figura 4. Variação da resistência à tração de acordo com o diâmetro das raízes e o seu conteúdo de celulose. $\bullet=$ Teor de celulose; $\bigcirc=$ Resistência à tração (Adaptado de GENET et al., 2005).

Por outro lado, autores têm indicado que a representação gráfica da relação entre resistência à tração e diâmetro de raízes pode apresentar problemas de autocorrelação (HALES et al., 2013). A alternativa mais simples a esse problema é optar por uma relação linear entre resistência máxima à tração $(\mathrm{N})$ e área transversal de raízes $\left(\mathrm{mm}^{2}\right)$ (HALES et al., 2009; HALES et al., 2013).

\section{Resistência do sistema solo-raiz}

As raízes das plantas integram o solo produzindo um material composto, onde atuam como fibras de grande resistência à tração (GRAY; LEISER, 1982; WU, 1995). A resistência mecânica do material composto, portanto, advém da resistência à tração das raízes e dos parâmetros de resistência do solo (Figura 5). Trata-se de um sistema análogo aos sistemas de reforço do solo comuns em Engenharia Civil, onde a massa é reforçada/estabilizada pela inclusão de materiais metálicos, sintéticos ou naturais (mas não vivos) (COPPIN; RICHARDS, 2007; GRAY; LEISER, 1982).

No solo, a presença de raízes tem efeito direto sobre a coesão (devido à resistência à tração das fibras), porém tem pouca ou nenhuma influência sobre o ângulo de atrito interno (COPPIN; RICHARD, 2007). A massa de raízes tende a diminuir de forma linear o efeito das 
tensões normais aplicadas no solo (GRAY; LEISER, 1982). Assim, a relação entre resistência ao cisalhamento (S) e tensão normal em solos com e sem raízes, demonstra o incremento da resistência ao cisalhamento devido à presença de raízes (Figura 6). As raízes aumentam a resistência ao cisalhamento por meio do incremento em coesão do solo (intercepto coesivo, $\mathrm{c}_{\mathrm{R}} \mathrm{R}$ ). Os valores médios de acréscimos de coesão proporcionados pelas raízes podem variar de 1 a $25 \mathrm{kPa}$ (NORRIS et al., 2008), dependendo do tipo e umidade do solo (estado de sucção), tipo de vegetação, idade, densidade de plantio, entre outros.
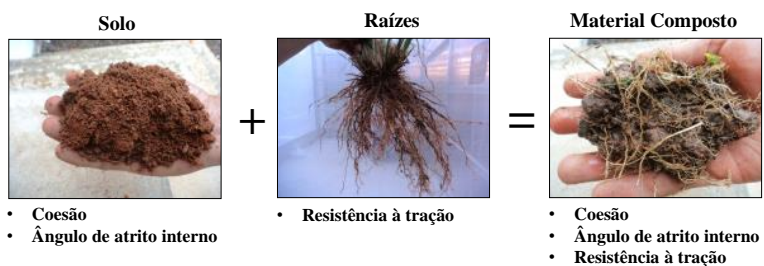

Figura 5. Representação da soma de características que compõem a resistência mecânica do sistema solo-raiz (Fonte: arquivo pessoal do autor).

A mobilização da resistência máxima das raízes que integram o material composto pode ocorrer tanto por arranquio (deslizamento devido à pequena força de atrito entre solo e raiz, Figura 7a), como por ruptura (rompimento por tração, Figura $7 b$ ).

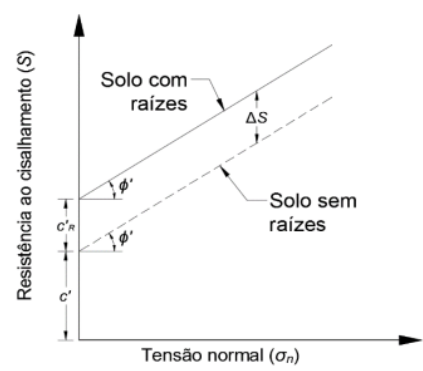

Figura 6. Efeito de reforço pelas raízes na resistência ao cisalhamento do solo. Onde: $\phi^{\prime}$, ângulo de atrito interno efetivo do solo; $c^{\prime}$, coesão efetiva; $c^{\prime}{ }_{R}$, aumento na coesão efetiva; $\Delta S$, aumento efetivo na resistência do solo ao cisalhamento devido ao reforço das raízes (Adaptado de COPPIN e RICHARDS, 2007).

Além das raízes reforçarem o solo por meio de sua resistência à tração, existe o acréscimo em resistência proporcionado por diminuição da poro-pressão da água (COPPIN; RICHARDS, 2007). Esse fenômeno é caracterizado pelo aumento da sucção mátrica do solo, ou seja, a aproximação entre partículas sólidas devido à diminuição do filme de água que as envolve (FREDLUND; RAHARDJO, 1993).

Em cálculos de estabilidade de taludes, efeitos de sucção têm pouco uso prático, por isso são normalmente negligenciados. Nesses cálculos, por segurança, normalmente se considerada a condição mais desfavorável à estabilidade, ou seja, a saturação da massa de solo. a)

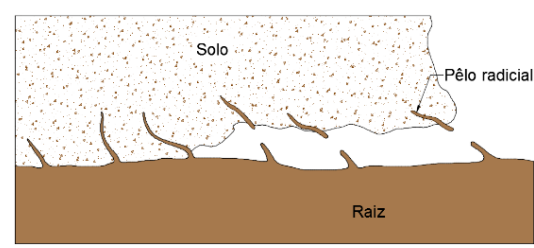

b)

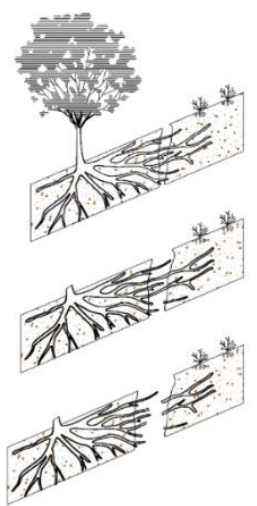

Figura 7. Formas de falha das raízes. a) Propagação da falha por superação das forças de adesão entre solo e raízes; b) Rompimento das raízes sob tração em diferentes estágios de deformação (Adaptado de SCHWARZ; COHEN; OR, 2010).

O critério de ruptura de Mohr-Coulomb, usado para descrever a resistência ao cisalhamento de solos saturados (COPPIN; RICHARDS, 2007), pode ser modificado para incluir os efeitos da vegetação em solos não saturados. Nesse caso, a resistência ao cisalhamento de um solo não saturado, em termos de tensão efetiva $\left(\sigma_{\mathrm{n}}{ }^{\prime}\right.$ $=\sigma_{\mathrm{n}}-\mathrm{u}$ ), e considerando o efeito da vegetação, é representada pela equação 2. Removendo o efeito da vegetação, tem-se a equação 3 que, em termos de tensão efetiva, representa a equação geral de resistência ao cisalhamento de solos não saturados (FREDLUND; RAHARDJO, 1993). Por fim, a simplificação da equação 3 , resulta, em termos de tensões efetivas, na equação geral de Mohr-Coulomb (Equação 4).

$$
\begin{gathered}
\mathrm{S}=\left(\mathrm{c}^{\prime}+\mathrm{c}_{\mathrm{R}}\right)+\left(\sigma_{\mathrm{n}}-\mathrm{u}_{\mathrm{a}}\right) \cdot \tan \phi^{\prime}+\left(\mathrm{u}_{\mathrm{a}}-\mathrm{u}\right) \cdot \tan \phi^{\mathrm{b}} \\
\mathrm{S}=\mathrm{c}^{\prime}+\left(\sigma_{\mathrm{n}}-\mathrm{u}_{\mathrm{a}}\right) \cdot \tan \phi^{\prime}+\left(\mathrm{u}_{\mathrm{a}}-\mathrm{u}\right) \cdot \tan \phi^{\mathrm{b}} \\
\mathrm{S}=\mathrm{c}^{\prime}+\sigma_{\mathrm{n}}^{\prime} \cdot \tan \phi^{\prime}
\end{gathered}
$$

Solos saturados geralmente perdem uma parcela significativa de coesão devido à redução das tensões de sucção (FREDLUND; RAHARDJO, 1993). Por essa razão, a contribuição das plantas para a resistência ao cisalhamento do solo tem sido considerada mais significativa em condições de solo saturado (COPPIN; RICHARDS, 2007). Assim, como a sucção ( $\left.u_{a}-u\right)$ se aproxima de zero na medida em que a saturação do solo é alcançada, em termos práticos, o termo referente a sucção pode ser desprezado, obtendo-se, em termos de tensões efetivas, a equação 5 (STOKES et al., 2008), que caracteriza a resistência ao cisalhamento de um solo saturado, com plantas. 


$$
\mathrm{S}=\left(\mathrm{c}^{\prime}+\mathrm{c}_{\mathrm{R}}^{\prime}\right)+\left(\sigma_{\mathrm{n}}-\mathrm{u}\right) \cdot \tan \phi^{\prime}
$$

Onde: $\mathrm{S}$, resistência ao cisalhamento do solo $(\mathrm{kPa}) ; \mathrm{c}^{\prime}$, coesão efetiva do solo $(\mathrm{kPa}) ; \mathrm{c}_{\mathrm{R}}^{\prime}$, contribuição das raízes à coesão do solo $(\mathrm{kPa}) ; \sigma_{\mathrm{n}}$, tensão normal $(\mathrm{kPa})$; $\sigma_{n}^{\prime}$, tensão normal efetiva $(\mathrm{kPa}) ; \phi^{\prime}$, ângulo de atrito interno efetivo do solo $\left({ }^{\circ}\right) ; \phi^{\text {b }}$, ângulo de atrito interno do solo $\left(^{\circ}\right)$ indicando a taxa de aumento na resistência ao cisalhamento relativa à sucção mátrica $\left(\mathrm{u}_{\mathrm{a}}-\mathrm{u}\right)$, com tensão normal no plano de ruptura $\left(\sigma_{n}-u_{a}\right)$ constante; $u_{a}$, poropressão do ar; u, poro-pressão da água; $\left(\mathrm{u}_{\mathrm{a}}-\mathrm{u}\right)$, sucção mátrica do solo.

A magnitude do reforço mecânico da vegetação é uma função das propriedades das raízes, referentes à densidade de comprimento radicular (root length density, comprimento de raízes por unidade de volume de solo) (LOADES et al., 2010), resistência à tração, módulo de tensão, relação comprimento/diâmetro, rugosidade da superfície, alinhamento (por exemplo, retilínea ou angulosa) (COPPIN; RICHARDS, 2007) e, orientação das fibrilas de celulose (ZHANG; CHEN; JIANG, 2014).

$\mathrm{O}$ aumento na coesão do solo, devido à presença de raízes, varia proporcionalmente à densidade de comprimento e de área das raízes (COPPIN; RICHARDS, 2007). Assim, em condições de avaliação da estabilidade de taludes, normalmente apenas raízes com até $8 \mathrm{~mm}$ de diâmetro são consideradas. Estudos in situ têm mostrado que raízes acima desse diâmetro não contribuem significativamente para aumentar a resistência ao cisalhamento, e por isso são consideradas como se fossem tirantes individuais, funcionando como um sistema de ancoragem (WU et al., 1988).

Medições de resistência do material composto (solo-raízes) são comumente realizadas usando ensaios de cisalhamento direto in situ, em laboratório, ou por estimativas separadas de resistência à tração de raízes e resistência ao cisalhamento do solo. A interação entre solo e raízes pode ser estimada utilizando-se o modelo de raiz perpendicular desenvolvido por $\mathrm{Wu}$ (1976), descrito no próximo tópico.

\section{Modelo teórico de avaliação do reforço do solo pelas raízes}

O modelo perpendicular de reforço radicular (WU, 1976) é o mais usado para estimar a contribuição das raízes no reforço do solo ao cisalhamento.

O modelo foi desenvolvido partindo do pressuposto de que as raízes são elementos flexíveis e elásticos (WU, 1976), que atravessam um determinado plano de ruptura na posição perpendicular (Figura 8). Trata-se de um modelo idealizado para raízes pivotantes ou alinhadas perpendicularmente (raízes secundárias). É uma simplificação necessária, uma vez que na natureza as raízes atravessam planos de ruptura em várias posições diferentes, o que dificulta em grande medida a obtenção de informações detalhadas.

De acordo com o modelo de reforço do solo por raízes, quando o material composto (solo e raízes) é cisalhado, a resistência à tração mobilizada nas raízes pode ser separada em componente tangencial, que resiste diretamente à força cisalhante, e componente normal, que aumenta a tensão de confinamento no plano de ruptura (WU, 1976). O modelo assume, implicitamente, que a resistência à tração das raízes é completamente mobilizada, não sendo por isso considerado o deslizamento das raízes no solo.

a)

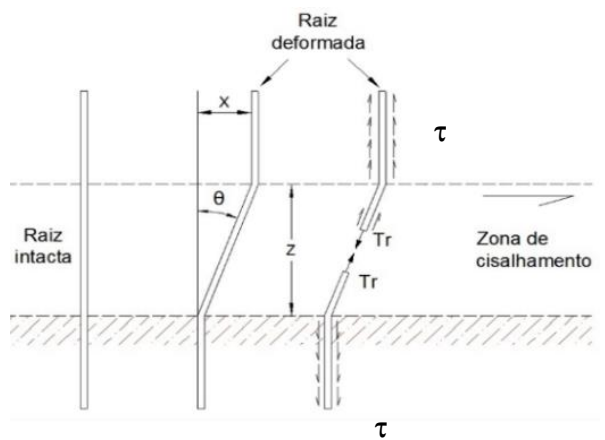

b)

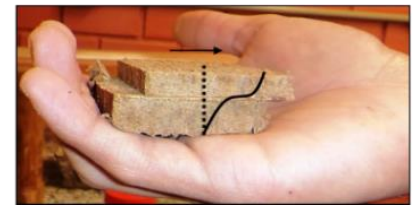

Figura 8. Modelo de reforço do solo por raiz perpendicular (WU, 1976). a) Raiz flexível e elástica alinhada perpendicularmente à superfície de ruptura no início do teste. Onde: $z$, espessura da zona de cisalhamento; $x$, deflexão horizontal da raiz; $\theta$, ângulo de distorção do cisalhamento; $T_{R}$, resistência da raiz à tração; $\tau$, força de atrito entre solo e raiz (Adaptado de GRAY e LEISER, 1982). b) representação de amostra de solo cisalhada com um segmento de raiz (linha pontilhada) inicialmente alinhado perpendicularmente ao plano de ruptura e posteriormente deformado (linha contínua).

Assume-se também que o ângulo de atrito interno do solo $(\phi)$ não é afetado pelo reforço. Assim, matematicamente, a resistência à tração nas fibras é transformada em aumento na resistência ao cisalhamento do solo (GRAY; LEISER, 1982), descrito pela equação 6.

$$
\Delta \mathrm{S}=\mathrm{t}_{\mathrm{R}} \cdot(\cos \theta \cdot \tan \phi+\operatorname{sen} \theta)
$$

Onde: $\Delta \mathrm{S}$, aumento na resistência ao cisalhamento proporcionado pelas raízes $(\mathrm{kPa}) ; \theta$, ângulo de distorção do cisalhamento $\left({ }^{\circ}\right) ; \phi$, ângulo de atrito interno do solo $\left({ }^{\circ}\right)$; $\mathrm{t}_{\mathrm{R}}$, resistência média das raízes por unidade de área $(\mathrm{kPa})$.

$\mathrm{O}$ valor de resistência média à tração das raízes por unidade de área de solo ( $\mathrm{t}_{\mathrm{R}}$ ) pode ser determinado pela multiplicação da resistência média à tração das raízes $\left(T_{R}\right)$ pela fração transversal de solo ocupado por raízes $\left(\mathrm{A}_{\mathrm{R}} / \mathrm{A}\right)$ (Equação 7) (GRAY; LEISER, 1982).

$$
t_{R}=T_{R} \cdot\left(A_{R} / A\right)
$$

Onde: $T_{R}$, resistência média à tração das raízes (MPa ou kPa); $A_{R} / A$, fração de área transversal de solo ocupada por raízes (adimensional; na língua inglesa é conhecida como RAR - Root Area Ratio). Assim, a 
resistência à tração das raízes é calculada pela equação 8 (BISCHETTI et al., 2005):

$$
\mathrm{T}_{\mathrm{R}}=\frac{\mathrm{F}_{\text {máx }}}{\mathrm{A}_{\mathrm{r}}}=\frac{\mathrm{F}_{\text {máx }}}{\left(\frac{\mathrm{D}^{2} \cdot \pi}{4}\right)}
$$

Onde: $F_{\text {máx }}$, força máxima de tração aplicada em um segmento de raiz $(\mathrm{kN}) ; A_{\mathrm{r}}$, área do segmento de raiz $\left(\mathrm{m}^{2}\right) ; \mathrm{D}$, diâmetro do segmento de raiz $(\mathrm{m})$.

A equação 6 é importante porque permite que a máxima contribuição das raízes para a resistência do solo seja estimada a partir do valor medido de resistência à tração $\left(T_{R}\right)$ e da fração da área transversal de solo ocupada por raízes $\left(A_{R} / A\right)$. A área transversal de raízes de uma planta $\left(A_{R}\right)$ é determinada pelo numerador da equação 9 (GRAY; LEISER, 1982).

$$
\frac{A_{R}}{A}=\frac{\sum n_{i} \cdot a_{i}}{A}
$$

Onde: $\mathrm{n}_{\mathrm{i}}$, número de raízes na classe de diâmetro $\mathrm{i}$; $\mathrm{a}_{\mathrm{i}}$, área transversal média das raízes na classe de diâmetro i $\left(\mathrm{m}^{2}\right)$; A, área transversal de solo da amostra considerada $\left(\mathrm{m}^{2}\right)$.

Quando os ensaios de tração são realizados para raízes individuais, o cálculo da contribuição média de resistência à tração por área de solo assume a equação 10 (GRAY; LEISER, 1982).

$$
\mathrm{t}_{\mathrm{R}}=\frac{\sum \mathrm{T}_{\mathrm{i}} \cdot \mathrm{n}_{\mathrm{i}} \cdot \mathrm{a}_{\mathrm{i}}}{\mathrm{A}}
$$

Onde: ' $T_{i}$, resistência à tração das raízes da classe i de diâmetro $(\mathrm{kPa})$.

Assim, a contribuição das raízes para a resistência do solo pode ser estimada com o uso das equações 6 e 7 (GRAY; LEISER, 1982). A única incerteza ou variável indeterminável nas equações é ângulo de distorção do cisalhamento $(\theta)$, que corresponde a inclinação máxima da raiz antes do rompimento. Esse ângulo, como visto na Figura 8a, varia de acordo com o deslocamento de cisalhamento $(\mathrm{x})$ e com a espessura da zona de cisalhamento $(\mathrm{z})$. Trabalhos tem indicado que os valores $\theta$ variam de $40^{\circ}-90^{\circ}$ (WALDRON, 1977; WU; MCKINNELL; SWANSTON, 1979). Essa variação, combinada com ângulos de atrito interno do solo de $25^{\circ}$ e $40^{\circ}$, faz com que o termo entre parênteses na equação 6 apresente valores de 1,0 a 1,3. Usualmente, o valor médio de 1,15 é o mais adotado, fazendo com que a equação 6 assuma a forma da equação 11 (COPPIN; RICHARDS, 2007).

$$
\Delta \mathrm{S}=1,15 \cdot \mathrm{t}_{\mathrm{R}}
$$

É importante observar que o modelo de raiz perpendicular assume que a ruptura das raízes ocorre por tração. Para essa pressuposição ser válida, a ruptura por deslizamento ou falha na adesão solo-raiz precisa ser prevenida. Nesse caso, a força de ligação entre solo e raízes deve exceder a resistência à tração das raízes. Isso é possível se as raízes apresentarem comprimento suficiente além da zona de ruptura e grande adesão ao solo (COPPIN; RICHARDS, 2007).
Embora recentemente tenham sido desenvolvidos outros modelos mais elaborados $\mathrm{e}$ complexos para a estimativa de contribuição das raízes para o reforço do solo, nomeadamente Fiber Bundle Model (FBM - POLLEN; SIMON, 2005) e Root Bundle Model (RBM - SCHWARZ et al., 2010), o modelo de raiz perpendicular de Wu (1976) ainda é o mais utilizado devido à sua simplicidade e facilidade de aplicação prática. No entanto, Pollen e Simon (2005) mostram que, para plantas com raízes laterais, somente uma fração das raízes cruzam a superfície potencial de ruptura e destas apenas algumas alcançam a resistência máxima à tração em uma solicitação, fazendo com que as equações 10 e 11 superestimem o valor de $\Delta \mathrm{S}$. O $\Delta \mathrm{S}$ corresponde a um valor determinado em teste de cisalhamento direto in situ ou em laboratório (Figura 8b), que corresponde a um valor observado de aumento de resistência ao cisalhamento proporcionado pelas raízes. Esse valor pode ser estimado com o modelo de raiz perpendicular de Wu (1976). Assim, apenas para raízes perpendiculares a equação 10 fornece resultados semelhantes de $\Delta \mathrm{S}$. Na correção de situações onde a posição inicial das raízes é desconhecida, a abordagem mais prática é a redução empírica da resistência ao cisalhamento estimada a partir da resistência à tração, utilizando um fator de 0,3 a 0,5 (WU, 2013).

\section{Ensaios para determinar o reforço dos solos pelas raízes}

A determinação do efeito mecânico das raízes sobre o reforço do solo é uma necessidade básica para a inclusão das plantas em cálculos de estabilidade de taludes. Principalmente por questões de representatividade, ensaios in situ são preferíveis para as determinações. Dois tipos de ensaio têm figurado na literatura como preferenciais para quantificar incrementos em resistência do solo devido à presença de raízes.

\section{Arranquio in situ}

Esse tipo de ensaio pode ser conduzido de duas formas distintas: arranquio de planta inteira ou arranquio de raízes individuais por classes de diâmetro (KARRENBERG et al., 2003; LIU et al., 2014; NORRIS et al., 2008). Em ambos se aplica uma força de tração para a extração total ou parcial das raízes do solo. A variável resposta, nesse caso, é a maior carga suportada pelo sistema radicular, a qual pode ser representada em termos de força ( $\mathrm{N}$ ou $\mathrm{kN}$ ) (LIU et al., 2014) ou de tensão ( $\mathrm{kPa}$ ) (WU et al., 2014), caso a área transversal das raízes seja medida.

$\mathrm{O}$ arranquio de planta inteira pode proporcionar a obtenção de informações mais representativas da contribuição total do sistema radicular para a resistência do solo. Por outro lado, elimina-se a possibilidade de identificar a contribuição de resistência de cada classe diamétrica das raízes. Isso porque a resistência total, na ausência de valores de diâmetro e resistência à tração de 
cada raiz, deve ser distribuída entre todas as classes de diâmetro (área total de raízes) encontradas na planta arrancada.

Nos testes de arranquio, durante a aplicação da força de tração, as fibras das raízes podem falhar por ruptura ou deslizamento (SCHWARZ et al., 2010). Na ruptura, a resistência das raízes é, em alguma parte de seus segmentos, superada pelo atrito entre solo e raízes (os segmentos que permanecem no solo). Essa é uma ação direta da área superficial específica das raízes de menor diâmetro. No deslizamento, a resistência das fibras supera o atrito entre solo e raízes e o segmento principal e suas ramificações são inteiramente extraídos do solo.

Nesses ensaios a grande maioria das raízes rompe. A extração de raízes inteiras é menos provável, mas pode acontecer em condições de solo saturado (COPPIN; RICHARDS, 2007).

A Figura 9 mostra um gráfico típico da relação força-deslocamento, obtido no arranquio de plantas inteiras de duas espécies reófitas nativas da Mata Atlântica, Phyllanthus sellowianus (Klotzsch) Müll. Arg. e Gymnanthes schottiana Müll. Arg., que são comumente utilizadas em obras de Engenharia Natural no sul do Brasil.

A primeira fase do ensaio é caracterizada pela ascensão dos valores de força, que inicia com o alongamento das raízes e termina quando a máxima resistência das fibras é mobilizada (máxima resistência à tração) (SCHWARZ et al., 2010).

A segunda fase é a de declínio ou deslizamento, onde existe uma resistência residual pelo atrito entre raízes rompidas e solo, ou pelo rompimento de raízes remanescentes (SCHWARZ; GIADROSSICH; COHEN, 2013). A principal característica dessa fase é o decréscimo em resistência até o sistema radicular ser completamente retirado do solo.

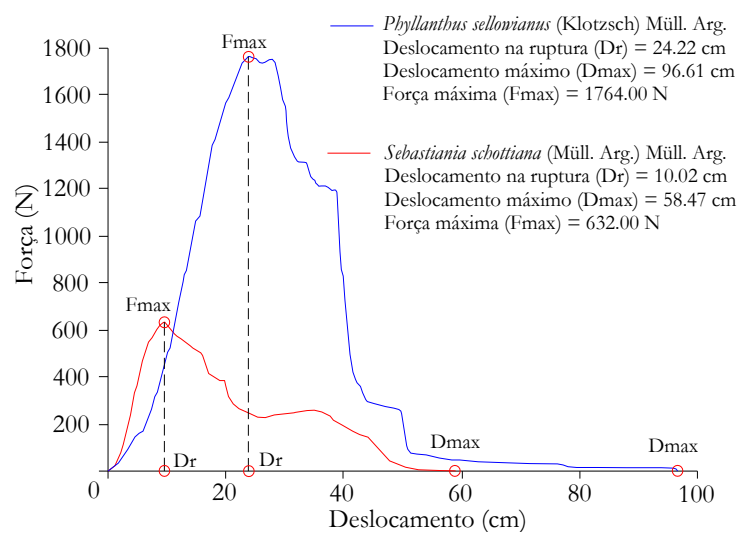

Figura 9. Arranquio de plantas inteiras. Relação típica entre força-deslocamento (Adaptado de HÖRBINGER, 2013).

No gráfico (Figura 9), cada pequeno pico, tanto na fase de ascensão quando na fase de decréscimo, representa a falha de um ou mais segmentos de raiz. Os valores de resistência das raízes ao arranquio, caso sejam provenientes de plantas propagadas a partir de estacas vivas, podem ser facilmente convertidos para valores de contribuição das raízes para a resistência ao cisalhamento $\left(\mathrm{C}_{\mathrm{R}}\right)(\mathrm{kPa})$, usando a equação 12 (WU et al., 2014).

$$
\mathrm{c}_{\mathrm{R}}=\frac{\mathrm{F}_{\text {máx }}}{\pi \cdot \mathrm{d} . \mathrm{L}} * 0,5
$$

Onde: $F_{\text {max }}$ é a resistência máxima ao arranquio $(\mathrm{kN})$, d é o diâmetro da estaca $(\mathrm{m})$ e $L$ é o comprimento da estaca (m). A multiplicação por 0,5 é uma medida conservadora, pois assume que as raízes estão presentes apenas em $50 \%$ da superfície de ruptura. Esse fator de redução é arbitrado, uma vez que o autor não apresenta bases empíricas que o corroborem.

É importante destacar que o método de arranquio é capaz de determinar apenas a resistência à tração das raízes. Nesse teste, a interação solo-raízes não é avaliada integralmente, ou seja, de modo a fornecer valores observados de contribuição para a resistência ao cisalhamento do solo $\left(\mathrm{c}_{\mathrm{R}}\right)$, variável que é utilizada no cálculo de estabilidade de taludes com vegetação. A obtenção dessa variável pode ser realizada através de teste de cisalhamento direto in situ.

\section{Cisalhamento direto in situ}

Esse tipo de teste segue o mesmo princípio dos testes de cisalhamento direto realizados em laboratório (LAMBE; WHITMAN, 1969) (Figura 10).

a)

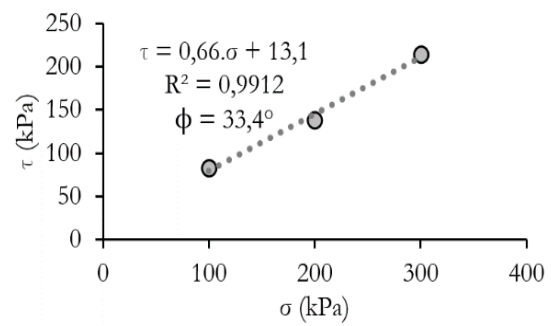

b)

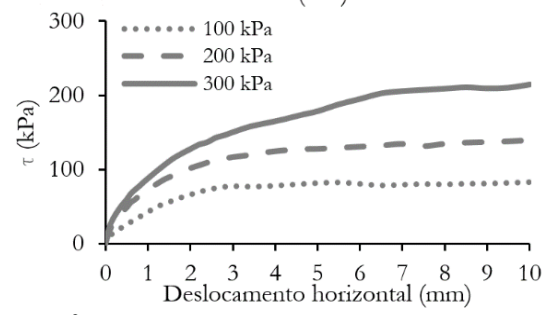

c)

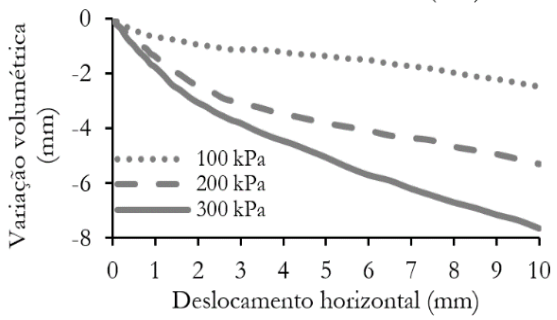

Figura 10. Informações obtidas em ensaios de cisalhamento direto em solo arenoso, em laboratório (Fonte: arquivo pessoal do autor). a) Representação da envoltória de Mohr-Coulomb. b) Relação entre tensão cisalhante aplicada e deslocamento horizontal. c) Relação entre variação volumétrica e deslocamento horizontal. $\tau$, tensão cisalhante $(\mathrm{kPa}) ; \phi$, ângulo de atrito interno $\left(^{\circ}\right)$. 
O objetivo dos ensaios de cisalhamento é a obtenção de uma envoltória de resistência, determinando-se o intercepto coesivo e o ângulo de atrito interno do solo (Figura 10a), além das relações entre tensão de cisalhamento e o deslocamento horizontal (Figura 10b) e entre variação volumétrica e deslocamento horizontal do corpo de prova (Figura 10c).

O esquema de um sistema para cisalhamento direto in situ, desenvolvido por Endo (1980), é apresentado na Figura 11. Esse sistema foi desenvolvido para incluir plantas inteiras em testes de cisalhamento e por isso utiliza corpos de prova de grandes dimensões

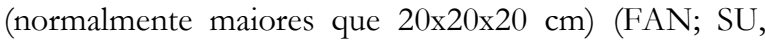
2008; ABDULLAH; OSMAN; ALI, 2011; PRETI; GIADROSSICH, 2009; GHESTEM et al., 2014). A Tabela 1 apresenta uma coletânea de dimensões de caixas utilizadas em testes de cisalhamento direto in situ.

Tabela 1. Dimensões utilizadas em caixas de ensaios de cisalhamento direto in situ.

\begin{tabular}{lc}
\multicolumn{1}{c}{ Autor } & $\begin{array}{c}\text { Dimensões (m) } \\
\text { (Comprimento; } \\
\text { Largura; Altura) }\end{array}$ \\
\hline Veylon et al. (2015) & 0,$50 ; 0,50 ; 0,30$ \\
Ghestem et al. (2014) & 0,$50 ; 0,50 ; 0,30$ \\
Abdullah, Osman e Ali (2011) & 0,$30 ; 0,30 ; 0,16$ \\
Comino, Marengo e Rolli (2010) & 0,$30 ; 0,30 ; 0,10$ \\
Mickovski e Van Beek (2009) & 0,$32 ; 0,32 ; 0,20$ \\
Fan e Su (2008) & 0,$30 ; 0,30 ; 0,20$ \\
Cammeraat, Van Beek e Kooijman (2005) & 0,$60 ; 0,60 ; 0,40$ \\
Lawrence, Rickson e Clark (1996) & 0,$25 ; 0,25 ; 0,10$ \\
Tobias (1995) & 0,$50 ; 0,50 ; 0,15$ \\
Endo (1980) & 0,$60 ; 0,12 ; 0,12$ \\
\hline \multicolumn{1}{c}{ Média } & 0,$42 ; 0,37 ; 0,20$ \\
\hline
\end{tabular}

Em laboratório, os corpos de prova de cisalhamento direto normalmente têm dimensões de $5 \times 5 \times 2 \mathrm{~cm}$ ou $10 \times 10 \times 2 \mathrm{~cm}$ (BRAJA, 2013).

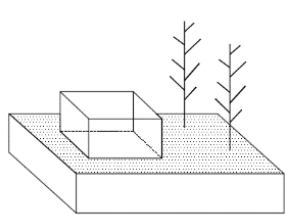

b)

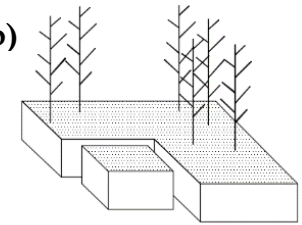

c)

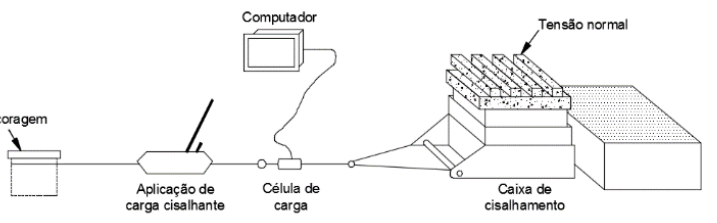

Figura 11. Representação esquemática de um equipamento para realização de testes de cisalhamento direto in situ, em blocos de solo com raízes. a) Caixa para moldar o bloco de solo com raízes; b) Caixa com bloco de solo e raízes; c) Sistema de cisalhamento preparado para a realização do teste (ENDO, 1980).

Os princípios de realização do ensaio são bem definidos. Como observado na Figura 11, o corpo de prova é moldado diretamente no solo e pode incluir ou não plantas. $\mathrm{Na}$ aplicação da tensão cisalhante $(\tau)$, apenas o bloco moldado é movimentado sobre a superfície de solo. Na posição vertical, a tensão normal constante $(\sigma)$ é aplicada. No caso representado na Figura 11, o carregamento vertical é realizado com blocos de concreto de peso conhecido. As tensões normais aplicadas são normalmente condizentes com a profundidade de atuação das raízes, comumente menor que $3 \mathrm{~m}$. A Tabela 2 apresenta uma coletânea de tensões normais aplicadas em testes de cisalhamento direto in situ.

Tabela 2. Valores de tensão normal utilizados em ensaios de cisalhamento direto in situ.

\begin{tabular}{lc}
\hline \multicolumn{1}{c}{ Autor } & $\begin{array}{c}\text { Tensão normal } \\
(\mathbf{k P a})\end{array}$ \\
\hline Veylon et al. (2015) & 3,$5 ; 4,7 ; 6,8$ \\
Ghestem et al. (2014) & 3,$5 ; 4,7 ; 6,8$ \\
Abdullah, Osman e Ali (2011) & 13,$3 ; 24,3$ \\
Mickovski e Van Beek (2009) & 1,$5 ; 3$ \\
Fan e Su (2008) & 2,$6 ; 5,4 ; 10,5 ; 21,3$ \\
Ali e Osman (2008) & $10 ; 20 ; 30$ \\
Cammeraat, Van Beek e Kooijman (2005) & 3,$3 ; 4,1$ \\
Lawrance, Rickson e Clark (1996) & 4,$7 ; 7,8 ; 10,9 ; 14,1$ \\
Tobias (1995) & 20 \\
\hline
\end{tabular}

É importante destacar que, contrariamente ao que alguns valores apresentados na Tabela 2 podem indicar, para se obter os parâmetros de resistência do solo (coesão e ângulo de atrito interno), é necessário que ao menos três blocos de solo com propriedades físicas semelhantes sejam cisalhados sob tensões normais diferentes. É este tipo de condução que possibilita a obtenção de uma equação linear, com intercepto (coesão) e coeficiente angular (ângulo de atrito interno).

A partir do ensaio de cisalhamento direto in situ, a contribuição das raízes para o aumento da coesão do solo é encontrada pela diferença entre os parâmetros de resistência de blocos com e sem raízes.

Ao cisalhar blocos de solo com plantas, as raízes podem romper, alongar ou deslizar (GRAY; SOTIR, 1996; SCHWARZ; COHEN; OR, 2010). Esses comportamentos podem ocorrer de modo individual ou conjunto no sistema radicular. $O$ rompimento e o deslizamento ocorrem da mesma maneira que no teste de arranquio, enquanto o alongamento depende do módulo de elasticidade das raízes (elasticidade e plasticidade). $\mathrm{Na}$ prática, o alongamento tem contribuição intermediária para a resistência. A contribuição total de uma raiz para o aumento da resistência do solo ocorre com sua ruptura (WU, 1995). Por essa razão, caso a ruptura das raízes não ocorra durante os testes de cisalhamento direto, a determinação da resistência à tração das raízes (WU, 2013) torna-se uma necessidade.

\section{Avaliação da estabilidade de taludes considerando a vegetação}

O conceito de fator de segurança é amplamente utilizado para avaliar a estabilidade de taludes e vertentes, e também de estruturas de contenção (HUBBLE, 2010). Trata-se de um valor adimensional que resulta da razão entre as forças resistentes e forças solicitantes que ocorrem ao longo de uma superfície potencial de ruptura 
(GUIDICINI; NIEBLE, 1983; BRAJA， 2013). As rupturas ocorrem quando esse valor atinge a unidade. Essa é a condição conhecida como equilíbrio limite, na qual as forças solicitantes igualam as forças resistentes.

Análises de estabilidade de taludes, considerando a influência das plantas, têm sido conduzidas tanto para taludes com ruptura translacional (taludes infinitos) como para taludes com ruptura rotacional (taludes circulares) (HUBBLE, 2010). Os primeiros ocorrem, normalmente, sobre superfícies de deslizamento preexistentes (rocha ou material pouco alterado), enquanto, nos segundos, não é possível fazer uma distinção entre a massa que deslizou e a que ficou estável (CLAGUE; STEAD, 2012).

Matematicamente, as rupturas translacionais e rotacionais são analisadas considerando fatias de solo submetidas a três campos de força distintos: (i) as forças devidas ao peso dos materiais; (ii) ao escoamento da água; e (iii) ao cisalhamento (FIORI; CARMIGNANI, 2009). $A$ análise de estabilidade consiste em considerar $\mathrm{O}$ equilíbrio dessas forças, uma vez que as duas primeiras se somam, e tendem a movimentar a massa de solo, enquanto a última atua contra essa movimentação (GERSCOVICH, 2016).

No talude de ruptura translacional, que tende a ter profundidade de ruptura semelhante ao longo de toda a sua extensão (superfície de ruptura plana), a análise de estabilidade é conduzida para uma única fatia (GUIDICINI; NIEBLE, 1983), enquanto no talude de ruptura circular, que tem profundidades variáveis, a análise é conduzida utilizando o método de várias fatias (FIORI; CARMIGNANI, 2009). Em deslizamento translacional a superfície potencial de ruptura tende a ser a interface entre solo e rocha, enquanto no rotacional, a superfície de ruptura é totalmente desconhecida, sendo encontrada por meio de cálculos iterativos, considerando-se aquela que apresentar o menor fator de segurança (BRAJA, 2013).

$\mathrm{Na}$ natureza, rupturas translacionais ocorrem principalmente em vertentes com inclinações acentuadas, sob influência de chuvas de longa duração. Na Serra do Mar, onde a estabilidade dos solos é em grande parte mantida devido às pressões de sucção, vulgarmente conhecida como "coesão aparente", o avanço de frentes de saturação é um dos principais mecanismos de perda de resistência e estabilidade de vertentes (WOLLE; CARVALHO, 1989). Rupturas rotacionais, além de outros ambientes, são comuns nas margens de cursos de água, principalmente em zonas de transporte e deposição, onde as camadas de solo tendem a ser mais espessas. Nesses locais, a elevação do nível de água até estágio de bankfull, ou vazão em que o canal é mais efetivo no transporte de sedimentos (DUNNE; LEOPOLD, 1978), atua favorecendo a saturação da massa e a competência do fluxo, ambos desfavoráveis à manutenção da estabilidade.

No uso de métodos para contabilizar a influência da vegetação, é importante que se considere o alcance do sistema radicular dentro do solo (WU, 1995), visto que raízes de gramíneas, arbustos e árvores atuam em diferentes profundidades. Mesmo plantas que têm potencial para desenvolver raízes profundas, também podem ser limitadas de acordo com as condições físicas, químicas e biológicas dos solos (BENGOUGH et al., 2011). Normalmente as influências mais significativas, de incrementos na resistência ao cisalhamento dos solos, ocorrem nas camadas mais superficiais do solo (ABERNETHY; RUTHERFORD, 2001), devido a maior densidade de área superficial e comprimento total das raízes.

A análise de estabilidade para determinar o fator de segurança de um talude vegetado pode incorporar cinco grandes efeitos da vegetação (COPPIN; RICHARDS, 2007): (i) Aumento da coesão efetiva do solo devido ao reforço da matriz de raízes $\left(\mathrm{c}^{\prime} \mathrm{R}\right.$ ); (ii) Aumento da coesão efetiva do solo como resultado da sucção proporcionada pela transpiração $\left(c^{\prime}{ }_{S}\right)$, ou um decréscimo na poro-pressão da água (u); (iii) Aumento da sobrecarga devido ao peso da vegetação $\left(\mathrm{S}_{\mathrm{W}}\right)$; (iv) Aumento da força de perturbação devido ao vento (D), agindo paralelamente à encosta; (v) Aumento da força de tração $(\mathrm{T})$, devido às raízes inclinadas de grande diâmetro atuando como elementos de tração.

A influência da vegetação na estabilidade de taludes é representada esquematicamente nas Figuras 12 e 13. Dos cinco efeitos possíveis da vegetação em taludes, alguns deles podem ter menor importância de acordo com o tipo de vegetação utilizada e também das condições do solo. Por exemplo, a sobrecarga pelo peso da vegetação $\left(\mathrm{S}_{\mathrm{W}}\right)$, a força de perturbação devido ao vento (D) e a força de tração ( $\mathrm{T}$ ) somente são significativas para árvores de grande porte, sendo, portanto, negligenciáveis no uso de gramíneas, ervas e arbustos. Em condições de solo saturado, que são as mais desfavoráveis, o efeito da sucção tende a zero, e por isso pode ser negligenciada a favor da segurança. Por fim, o efeito restante, e por isso o de maior importância, é o aumento da coesão efetiva do solo devido ao reforço da matriz do solo pelas raízes.

Os métodos de análise de estabilidade de taludes podem ser modificados para incluir o efeito da vegetação. $\mathrm{O}$ método mais comum usado na abordagem de estabilidade de um talude de terra é o de equilíbrio limite, no qual se assume que o critério de ruptura linear (MohrCoulomb) é satisfeito ao longo de toda a superfície de deslizamento e que existe um fator de segurança constante ao longo desta superfície (MASSAD, 2010). Como descrito no início da seção, as análises podem ser realizadas para taludes de ruptura translacional e rotacional.

No uso de análise de tensões efetivas pelo método de talude infinito, o fator de segurança sem a vegetação pode ser definido pela equação 13 (STYCZEN; MORGAN, 1995).

$$
\mathrm{FS}=\frac{\mathrm{c}^{\prime}+\left(\gamma \cdot z-\gamma_{\mathrm{w}} \cdot \mathrm{h}_{\mathrm{w}}\right) \cdot \cos ^{2} \beta \cdot \tan \phi^{\prime}}{\gamma \cdot z \cdot \operatorname{sen} \beta \cdot \cos \beta}
$$

Onde: $\gamma$, peso específico do solo $\left(\mathrm{kN} / \mathrm{m}^{3}\right) ; \mathrm{z}$, altura do solo acima da superfície de ruptura $(\mathrm{m}) ; \beta$, 
ângulo do talude $\left({ }^{\circ}\right) ; \gamma_{\mathrm{w}}$, peso específico da água $\left(\mathrm{kN} / \mathrm{m}^{3}\right)$; $\mathrm{h}_{\mathrm{w}}$, Altura da superfície freática acima da superfície de deslizamento $(\mathrm{m}) ; \phi^{\prime}$, ângulo de atrito interno do solo $\left({ }^{\circ}\right)$.

Assim, para um talude infinito com influência da vegetação (Figura 12), o cálculo do fator de segurança é descrito pela equação 14 (COPPIN; RICHARDS, 2007).

$\mathrm{FS}=\frac{\left(\mathrm{c}^{\prime}+\mathrm{c}_{\mathrm{R}}^{\prime}\right)+\left\{\left[\left(\gamma \cdot \mathrm{z}-\gamma_{\mathrm{W}} \cdot \mathrm{h}_{\mathrm{W}}\right)+\mathrm{S}_{\mathrm{W}}\right] \cdot \cos ^{2} \beta+\mathrm{T} \cdot \operatorname{sen} \theta\right\} \cdot \tan \phi^{\prime}+\mathrm{T} \cdot \cos \theta}{\left[\left(\gamma \cdot \mathrm{z}+\mathrm{S}_{\mathrm{W}}\right) \cdot \operatorname{sen} \beta+\mathrm{D}\right] \cdot \cos \beta}$

Onde: $c_{\mathrm{R}}^{\prime}$, Coesão efetiva do solo acentuada devido ao reforço da matriz radicular da vegetação ao longo da superfície de deslizamento $(\mathrm{kPa}) ; \mathrm{S}_{\mathrm{W}}$, sobrecarga devido ao peso da vegetação $(\mathrm{kPa}) ; \mathrm{h}_{\mathrm{w}}$, altura vertical do lençol freático acima do plano de deslizamento com a vegetação (m); T, Força de tensão das raízes atuando na base da superfície de deslizamento $(\mathrm{kN} / \mathrm{m}) ; \theta$, ângulo entre as raízes e o plano de ruptura $\left({ }^{\circ}\right) ; \mathrm{e} \mathrm{D}$, força de carga do vento paralela ao talude $(\mathrm{kN} / \mathrm{m})$.

É importante notar que na equação 14 , o aumento da coesão efetiva do solo como resultado da sucção proporcionada pela transpiração das plantas $\left(c^{\prime}\right.$ S), foi negligenciado. Essa variável, por vezes, também é expressa como diminuição da poro-pressão devido à transpiração das plantas $\left(\mathrm{u}_{\mathrm{v}}\right)$.

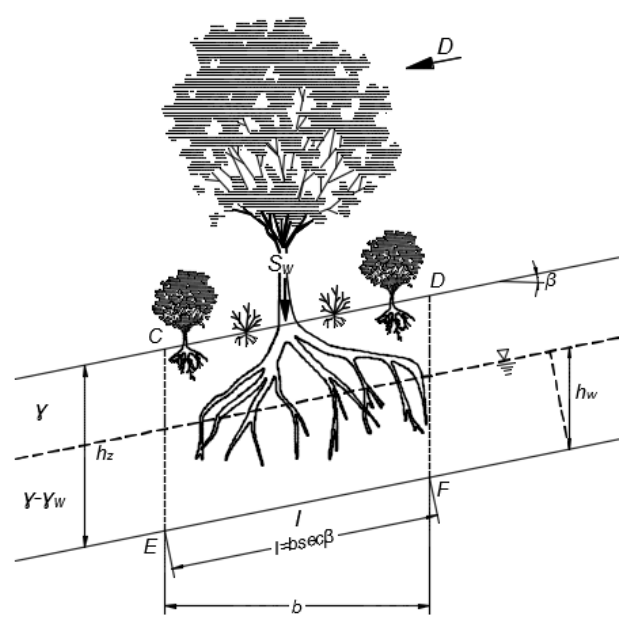

Figura 12. Forças atuantes na fatia de um talude infinito com vegetação (Adaptado de COPPIN e RICHARDS, 2007). Onde: $D$, carga do vento paralela ao talude; Sw, sobrecarga devido ao peso da vegetação; C, D, E e F são as posições que delimitam a fatia de solo analisada; $\beta$, ângulo de inclinação do talude; $\gamma$, peso específico do solo; $\gamma_{\mathrm{w}}$, peso específico da água; $\mathrm{h}_{\mathrm{z}}$, altura de solo acima da superfície de ruptura; $h_{w}$, altura da água acima da superfície de ruptura; $\theta$, ângulo entre raízes e superfície de ruptura; $b$, largura da fatia; 1 , comprimento da base da fatia (b.sec $\beta$ ).

O método de fatias de Fellenius (1936), usado para a análise de estabilidade de rupturas circulares, também pode ser adaptado para incluir os efeitos da vegetação (GREENWOOD, 1983). Na prática, o método de Fellenius tende a ser bastante conservador. Isso ocorre devido à pressuposição de que a infiltração e fluxos de água no interior do talude ocorrem paralelas à superfície de deslizamento, o que não é apropriado quando a superfície inicia no topo e emerge na base (pé) do talude (COPPIN; RICHARDS, 2007). Greenwood (1983), considerando essa observação, propôs uma simplificação do método, assumindo uma superfície de ruptura horizontal em cada fatia, sendo o fator de segurança obtido por meio da equação 15 .

$$
\mathrm{FS}=\frac{\sum \mathrm{c}^{\prime} \cdot \mathrm{b} \cdot \sec \alpha+(\mathrm{W}-\mathrm{u} \cdot \mathrm{b}) \cdot \cos \alpha \cdot \tan \phi^{\prime}}{\sum \mathrm{W} \cdot \sin \alpha}
$$

Onde: b, largura da fatia; W, peso total da fatia de solo $(\mathrm{kPa})$; u, poro-pressão causada pela água na superfície de ruptura $\left(\gamma_{\mathrm{w}} \cdot \mathrm{h}_{\mathrm{w}}\right)(\mathrm{kPa}) ; \alpha$, ângulo de inclinação da base da fatia com a horizontal $\left(^{\circ}\right) ; \phi^{\prime}$, ângulo de atrito interno do solo $\left(^{\circ}\right)$.

Considerando os parâmetros da vegetação a equação fica (COPPIN; RICHARDS, 2007):

$\mathrm{FS}=\frac{\sum\left\{\left(\mathrm{c}^{\prime}+\mathrm{c}_{\mathrm{R}}^{\prime}\right) \cdot \mathrm{b} \cdot \sec \alpha+\left[\left(\left(\mathrm{W}+\mathrm{S}_{\mathrm{W}}\right)-\left(\mathrm{u}-\mathrm{u}_{\mathrm{v}}\right) \cdot \mathrm{b}\right) \cdot \cos \alpha-\mathrm{D} \cdot \operatorname{sen}(\alpha-\beta)+\mathrm{T} \cdot \operatorname{sen} \theta\right] \cdot \tan \phi^{\prime}+\mathrm{T} \cdot \cos \theta\right]}{\sum\left[\left(\mathrm{W}+\mathrm{S}_{\mathrm{W}}\right) \cdot \operatorname{sen} \alpha+\mathrm{D} \cdot \cos (\alpha-\beta)\right]}$

Onde: $\mathrm{u}_{\mathrm{v}}$ é a redução da poro-pressão da água devido à transpiração proporcionada pelas plantas $(\mathrm{kPa})$.

A Figura 13 representa esquematicamente a situação em que a equação 16 é empregada.

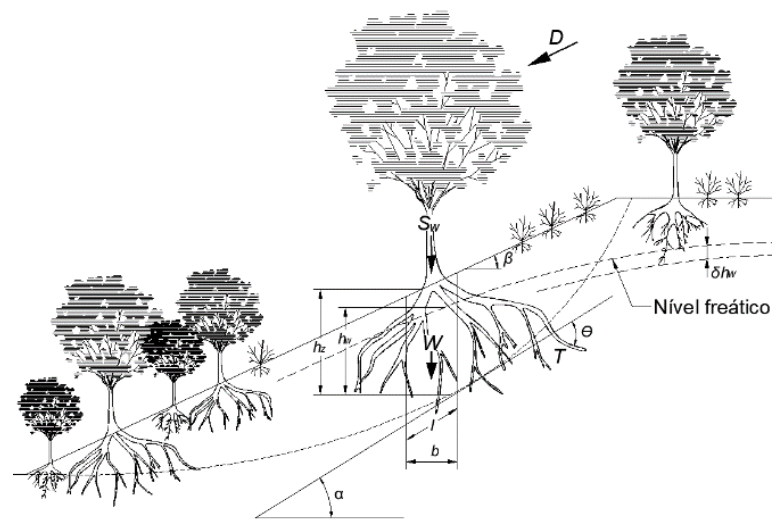

Figura 13. Talude com ruptura rotacional, mostrando as principais influências da vegetação e os parâmetros aplicados na análise de estabilidade (Adaptado de COPPIN e RICHARDS, 2007). D, carga do vento paralela ao talude; Sw, sobrecarga devido a massa da vegetação; $h_{z}$, altura de solo acima da superfície de ruptura; $h_{w}$ : altura da água acima da superfície de ruptura; $\delta \mathrm{h}_{\mathrm{w}}$, variação no nível do lençol freático; $\beta$, ângulo de inclinação do talude; $\theta$, ângulo entre raízes e superfície de ruptura; $\alpha$, ângulo de inclinação da base da fatia com a horizontal; 1, comprimento da base da fatia (b.sec $\alpha$ ); $T$, força de tração das raízes atuando na base da superfície de ruptura; W, peso total da fatia de solo; $b$, largura da fatia.

A inclusão de valores de coesão efetiva do solo devido ao reforço da matriz por raízes $\left(c^{\prime}{ }_{R}\right)$ em análises de estabilidade de taludes tem influência considerável no aumento dos fatores de segurança (COPPIN; RICHARDS, 2007; NORRIS et al., 2008). Pequenos aumentos na ordem de 1 a $5 \mathrm{kPa}$ na resistência ao cisalhamento são suficientes para proporcionar grandes 
melhorias na estabilidade de taludes (GREENWAY, 1987).

Assim, o principal efeito técnico buscado pelo uso de plantas em taludes é o de aumentar valores de fator de segurança com o intuito de melhorar sua estabilidade. De um ponto de vista conservador, a condição de estabilidade é atingida quando o valor do fator de segurança for igual ou maior que 1,5 (ABNT-NBR 11682, 2009). A título de exemplo, em estudo realizado por $\mathrm{Wu}$ et al. (2014), o uso de estacas vivas de Salix sp., com até $1,0 \mathrm{~m}$ de comprimento, entre 13 e 25 meses de idade, favoreceu incrementos na ordem de 33 a $68 \mathrm{kPa}$ na resistência ao cisalhamento do solo de um talude, proporcionando valores elevados de fator de segurança $(>5)$. Contudo, é importante considerar que cada espécie vegetal, por razões já destacadas, tem potenciais diferentes de contribuição à resistência ao cisalhamento dos solos.

\section{CONCLUSÃO}

O entendimento dos conceitos relacionados com o uso e avaliação da eficiência das plantas em obras de Engenharia Natural é de fundamental importância para o avanço técnico e científico desta área do conhecimento.

As raízes das plantas, por meio de diferentes mecanismos, demonstram a capacidade de aumentar a resistência dos solos. Essa contribuição é resultado da resistência à tração, densidade, comprimento, diâmetro e área superficial específica das raízes, assim como os efeitos associados de direcionamento, drenagem e sucção da água no solo. De modo geral, tais mecanismos tendem atuar de maneira conjunta na manutenção da estabilidade de taludes.

Os métodos de avaliação do reforço dos solos devido à presença de raízes devem ser realizados em condições de campo, para que assim seja considerada a variação estrutural do solo com plantas em condições naturais de desenvolvimento.

\section{REFERÊNCIAS}

ABDULLAH, M. N.; OSMAN, M.; ALI, F. H. Soil-root shear strength properties of some slope plants. Sains Malaysiana, v. 40, n. 10, p. 1065-1073, 2011.

ABERNETHY, B.; RUTHERFORD, I. D. The distribution and strength of riparian tree roots in relation to riverbank reinforcement. Hydrological Processes, v. 15, n. 1, p. 63-79, 2001.

ABNT. Associação Brasileira de Normas Técnicas. NBR 11682: Estabilidade de Encostas. Rio de Janeiro, 2009.

ALI, F. H.; OSMAN, N. Shear strength of a soil containing vegetation roots. Soils and Foundations, v. 48, n. 4, p. 587-596, 2008.
BENGOUGH, A.G.; MCKENZIE, B.M.; HALLET'T, P.D.; VALENTINE, T.A. Root elongation, water stress, and mechanical impedance: a review of limiting stresses and beneficial root tip traits. Journal of Experimental Botany, v. 62 , n. 1, p. 59-68, 2011.

BISCHETTI, G. B.; CHIARADIA, E. A.; SIMONATO, T.; SPEZIALI, B.; VITALI, B.; VULLO, P.; ZOCCO, A. Root strength and root area ratio of forests species in Lombardy (Northern Italy). Plant and Soil, v. 278, n. 1, p. 11-22, 2005.

BÖHM, W. Methods of studying root systems. Berlin Heilderberg: Springer-Verlag, v. 33, 1979. 188 p.

BRAJA, M. D. Fundamentos de Engenharia Geotécnica. Tradução da $7^{\mathrm{a}}$ ed. Norte Americana. São Paulo Cengage Learning, 2013. 560 p.

CAMMERAAT, E.; VAN BEEK, R.; KOOIJMAN, A. Vegetation succession and its consequences for slope stability in SE Spain. Plant and Soil, v. 278, n. 1, p. 135147, 2005.

CLAGUE, J. J.; STEAD, D. Landslides: Types, Mechanisms and Modeling. Cambridge University Press, 2012. 435 p.

COMINO, E.; MARENGO, P.; ROLLI, V. Root reinforcement effect of different grass species: A comparison between experimental and models results. Soil and Tillage Research, v. 110, n. 1, p. 60-68, 2010.

COPPIN, N. J.; RICHARDS, I. J. Use of vegetation in civil engineering. Construction Industry Research and Information Association, Butterworths, London, 2007. $312 \mathrm{p}$.

COUTTS, M. P. Root architecture and tree stability. Plant and Soil, v. 71, n. 1, p. 171-188, 1983.

DANJON, F.; KHUDER, H.; STOKES, A. Deep phenotyping of coarse root architecture in R. pseudoacacia reveals that tree root system plasticity is confined within its architectural model. Plos One, v. 8, n. 12, p. 1-15, 2013.

DE BAETS, S.; POESEN, J.; REUBENS, B.; WEMANS, K.; DE BAERDEMAEKER, J.; MUYS, B. Root tensile Strength and root distribution of typical Mediterranean plant species and their contribution to soil shear strength. Plant and Soil, v. 305, n. 1, p. 207-226, 2008.

DUNNE, T.; LEOPOLD, L. B. Water in environmental planning. $1^{\mathrm{a}} \mathrm{ed}$. San Francisco: W.H. Freeman \& Company San Francisco, 1978. 818 p.

DURLO, M.; SUTILI, F. Bioengenharia - Manejo biotécnico de cursos de água. $3^{\mathrm{a}}$ ed. Santa Maria: Pallotti, 2014. 
ENDO, T. Effect of tree roots upon the shear strength of soil. Japan Agricultural Research Quarterly, v. 14, n. 2 p.112-115, 1980.

FAN, C. C.; SU, C. F. Role of roots in the shear strength of root-reinforced soils with high moisture content. Ecological Engineering, v. 33, n. 2, p. 157-166, 2008.

FELLENIUS, W. Calculations of the stability of earth dams. In: Trans. 2nd Congress on Large Dams, Washington DC, v. 4, 1936. 445 p.

FIORI, A. P.; CARMIGNANI, L. Fundamentos de mecânica dos solos e das rochas: aplicações na estabilidade de taludes. $2^{\mathrm{a}}$ ed. Revisada e ampliada. Ed. UFPR - Curitiba, PR, 2009.

FREDLUND, D. G.; RAHARDJO, H. Soil mechanics for unsaturated soils. John Wiley \& Sons, New York, 1993.

GENET, M.; STOKES, A.; SALIN, F.; MICKOVSKI, S. B.; FOURCAUD, T.; DUMAIL, J. F.; VAN BEEK, R. The influence of cellulose content on tensile strength in tree roots. Plant and Soil, v. 278, n. 1, p. 1-9, 2005.

GERSCOVICH, D. M. Estabilidade de taludes. $2^{\mathrm{a}} \mathrm{ed}$. Oficina de Textos: São Paulo, 2016. 192 p.

GHESTEM, M.; VEYLON, G.; BERNARD, A.; VANEL, Q.; STOKES, A. Influence of plant root system morphology and architectural traits on soil shear resistance. Plant and Soil, v. 377, n. 1, p. 43-61, 2014.

GRAY, D. H.; LEISER, A. J. Biotechnical Slope Protection and Erosion Control. Van Nostrand Reinhold, New York, 1982. $271 \mathrm{p}$.

GRAY, D. H.; SOTIR, R. B. Biotechnical and Soil Bioengineering Slope Stabilization. John Wiley and Sons, Inc., New York, 1996. 400 p.

GREENWAY, D. R. Vegetation and slope stability. In: ANDERSON, M. G.; RICHARDS, K. S. (eds.) Slope stability, New York: Wiley, 1987. p. 187-230.

GREENWOOD, J. R. A simple approach to slope stability. Ground Engineering, v. 16, n. 4, p. 45-98, 1983.

GUIDICINI, G.; NIEBLE, C. M. Estabilidade de taludes naturais e de escavação. Ed. Blucher, $2^{\mathrm{a}}$ ed., São Paulo, 1983.

GYSSELS, G.; POESEN, J.; BOCHET, E.; LI, Y. Impact of plant roots on the resistance of soils to erosion by water: a review. Progress in Physical Geography, v. 29, n. 2, p. 189-217, 2005

HALES, T. C.; FORD, C. R.; HWANG, T.; VOSE, J. M.; BAND, L. E. Topographic and ecologic controls on root reinforcement. Journal of Geophysical Research, v. 114, n. F03013, p. 1-17, 2009.
HALES, T. C.; HAWTHORNE, C. C.; LOVELL, L.; EVANS, S. L. Assessing the accuracy of simple field based root strength measurements. Plant and Soil, v. 372, n. 1, p. 553-565, 2013.

HÖRBINGER, S. A pull out test of Phyllanthus sellowianus and Sebastiania schottiana and development of soil bioengineering constructions in southern Brazil. 2013. 91 f. Master thesis Universität für Bodenkultur Wien, Wien, 2013.

HUBBLE, T. C. T. Improving the stream of consciousness: A nomenclature for describing the factor of safety in river bank stability analysis. Ecological Engineering, v. 36, n. 12, p. 1765-1768, 2010.

KARRENBERG, S.; BLASER, S.; KOLLMANN, J.; SPECK, T.; EDWARDS, P.J. Root anchorage of saplings and cuttings of woody pioneer species in a riparian environment. Functional Ecology, v. 17, n. 2, p. 170-177, 2003.

KOKUTSE, N.; FOURCAUD, T.; KOKOU, K.; NEGLO, K.; LAC, P. 3D numerical modelling and analysis of the influence of forest structure on hill slopes stability. In: MARUI, H.; MARUTANI, T.; WATANABE, N.; KAWABE, H.; GONDA, Y.; KIMURA, M.; OCHIAI, H.; OGAWA, K.; FIEBIGER, G.; HEUMADER, J.; RUDOLF-MIKLAU, F.; KIENHOLZ, H.; MIKOS, M. (Eds) Interpraevent 2006: Disaster mitigation of debris flows, slope failures and landslides. Universal Academy Press, Tokyo, 2006. P. 561-567.

LAMBE, T. W.; WHITMAN, R. V. Soil Mechanics. New York: J. Wile, 1969. 535 p.

LAWRENCE, C. J.; RICKSON, R. J.; CLARK, J. E. The effect of grass roots on the shear strength of colluvial soils in Nepal. In ANDERSON, M. G.; BROOKS, S. M. (Eds), Advances in Hillslope Processes, John Wiley, Chichester, 1996. p. 857-868.

LETEY, J. Relationship between soil physical properties and crop production. Advances in Soil Sciences, v. 1, n. 1, p. 277-293, 1985.

LIU, Y.; RAUCH, H.P.; ZHANG, J.; YANG, X.; GAO, $J$. Development and soil reinforcement characteristics of five native species planted as cuttings in local area of Beijing. Ecological Engineering, v. 71, n. 1, p. 190-196, 2014.

LOADES, K.W.; BENGOUGH, A.G.; BRANSBY, M.F., HALLETT, P.D. Biomechanics of nodal, seminal and lateral roots of barley: effects of diameter, waterlogging and mechanical impedance. Plant and Soil, v. 370, n. 1-2, p. 407-418, 2013 a. 
LOADES, K.W.; BENGOUGH, A.G.; BRANSBY, M.F.; HALLETT, P.D. Reinforcement of soil by fibrous roots. In: TIMLIN, D.; AHUJA, L.R. (Eds.) Enhancing Understanding and Quantification of Soil-Root Growth Interactions, Adv. Agric. Syst. Model. 4. ASA, CSSA, SSSA., Madison, WI. 2013b. p. 197-228.

LOADES, K.W.; BENGOUGH, A.G.; BRANSBY, M.F.; HALLETT, P. D. Effect of root age on the biomechanics of seminal and nodal roots of barley (Hordeum vulgare L.) in contrasting soil environments. Plant and soil, v. 395, n. 1-2, p. 253-261, 2015.

LOADES, K.W.; BENGOUGH, A.G.; BRANSBY, M.F.; HALLETT, P.D. Planting density influence on fibrous root reinforcement of soils. Ecological Engineering, v. 36, n. 3, p. 276-284, 2010.

MAFFRA, C. R. B. Metodologia para projetos de Engenharia Natural para obras de infraestrutura. 2014. 150 f. Dissertação (Mestrado em Engenharia Florestal) - Universidade Federal de Santa Maria, Santa Maria, 2014.

MASSAD, F. Obras de Terra: Curso Básico de Geotecnia. $2^{\text {a }}$ ed., São Paulo, 2010. 216 p.

MATTIA, C.; BISCHETTI, G. B.; GENTILE, F. Biotechnical characteristics of root systems of typical Mediterranean species. Plant and Soil, v. 278, n. 1, p. 2332, 2005.

MICKOVSKI, S. B.; VAN BEEK, L. P. H. Root morphology and effects on soil reinforcement and slope stability of young vetiver (Vetiveria zizanioides) plants grown in semi-arid climate. Plant and Soil, v. 324, n. 1, p. 43-56, 2009.

MORGAN, R. P. C.; RICKSON, R. J. Slope stabilization and erosion control: $A$ bioengineering approach. London: $\mathrm{E} \&$ FN SPON, 1995. 274 p.

NICOLL, B. C.; GARDINER, B. A.; RAYNER, B.; PEACE, A. B. The architecture of Picea sitchensis structural root systems on horizontal and slop terrain. Trees, v. 20, n. 6, p. 701-712, 2006.

NILAWEERA, N. S.; NUTALAYA, P. Role of tree roots in slope stabilization. Bulletin on Engineering Geology and the Environment, v. 57, n. 4, p. 337-342, 1999.

NORRIS. J. E.; GREENWOOD, J. R.; ACHIM, A.; GARDINER, B. A.; NICOLL, B. C.; CAMERAAT, E; MICKOVSKI, S. B. Hazard Assessment of Vegetated Slopes. In: NORRIS, E. J.; STOKES, A.; MICKOVSKI, S. B.; CAMMERAAT, E.; VAN BEEK, R.; NICOLL, B. C.; ACHIM, A. (eds.) Slope Stability and Erosion Control: Ecotechnological Solutions. Springer, Dordrecht, Netherlands, 2008. p. 119-166.
OPERSTEIN, V.; FRYDMAN, S. The influence of vegetation on soil strength. Ground Improvement, v. 4, n. 2, p. 81-89, 2000.

POLLEN, N.; SIMON, A. Estimating the mechanical effects of riparian vegetation on stream bank stability using a fiber bundle model. Water Resources Research, v. 41, n. 7 , p. $1-11,2005$.

PRETI, F.; GIADROSSICH, F. Root reinforcement and slope bioengineering stabilization by Spanish Broom (Spartium junceum L.). Hydrology and Earth System Science, v. 13, n. 1, p. 1713-1726, 2009.

REUBENS, B.; POENSEN, J.; DANJON, F.; GEUDENS, G.; MUYS, B. The role of fine and coarse roots in shallow slope stability and soil erosion control with a focus on root system architecture: a review. Trees, v. 21, n. 4, p. 385-402, 2007.

TOBIAS, S. Shear strength of the soil root bond system. In: BARKER, D. H. Vegetation and slopes. Thomas Telford, London, 1995. p. 280-285.

SCHIECHTL, H. M.; STERN, R. Ground bioengineering techniques for Slope protection and erosion control. Blackwell Science Publications, Oxford, 1996. 176 p.

SCHWARZ, M.; COHEN, D.; OR, D. Root-soil mechanical interactions during pullout and failure or root bundles. Journal of Geophysical Research, v. 115, n. 4, p. 1-19, 2010.

SCHWARZ, M.; PRETI, F.; GIADROSSICH, F.; LEHMANN, P.; OR, D. Quantifying the role of vegetation in slope stability: A case study in Tuscany (Italy). Ecological Engineering, v. 36, n. 3, p. 285-291, 2010.

SCHWARZ, M.; GIADROSSICH, F.; COHEN, D. Modeling root reinforcement using a root-failure Weilbull survival function. Hydrology and Earth System Sciences, v. 17, n. 11, p. 4367-4377, 2013.

STOKES, A.; MATTHECK, C. Variation of root strength in tree roots. Journal Experimental Botany, v. 47, n. 5, p. 693-699, 1996.

STOKES, A.; NORRIS, J. E.; VAN BEEK, L. P. H.; BOGAARD, T.; MICKOVSKI, S. B.; JENNER, A.; DI LORIO, A.; FOURCAUD, T. How vegetation reinforces soil on slopes. In: NORRIS, E. J.; STOKES, A.; MICKOVSKI, S. B.; CAMMERAAT, E.; VAN BEEK, R.; NICOLL, B. C.; ACHIM, A. (eds.) Slope Stability and Erosion Control: Ecotechnological Solutions. Springer, Dordrecht, Netherlands, 2008. p. 65-118. 
STYCZEN, M. E.; MORGAN, R. P. C. Engineering Properties of Vegetation. In: MORGAN, R. P. C.; RICKSON, R. J. (eds) Slope Stabilization and Erosion control: A Bioengineering Approach. E\&FN Spon, London, 1995. p. 5-58.

VAN BEEK, R.; CAMMERAAT, E.; ANDREU, V.; MICKOVSKI, S. B. Hillslope processes: mass wasting, slope stability and erosion. In: NORRIS, E. J.; STOKES, A.; MICKOVSKI, S. B.; CAMMERAAT, E.; VAN BEEK, R.; NICOLL, B. C.; ACHIM, A. (eds.) Slope Stability and Erosion Control: Ecotechnological Solutions. Springer, Dordrecht, Netherlands, 2008. p. 17-64.

VERGANI, C.; CHIARADIA, E. A.; BASSANELLI, C.; BISCHETTI, G. B. Root strength and density decay after felling in a Silver Fir-Norway stand in the Italian Alps. Plant and Soil, v. 377, n. 1, p. 63-81, 2014.

VEYLON, G.; GHESTEM, M.; STOKES, A.; BERNARD A. Quantification of mechanical and hydric components of soil reinforcement by plant roots. Canadian Geotechnical Journal, v. 52, n. 11, p. 1-11, 2015.

WALDRON, L. J. The shear resistance of rootpermeated homogeneous and stratified soil. Soil Science Society of America Journal, v. 41, n. 5, p. 843-849, 1977.

WOLLE, C. M.; CARVALHO, C. S. Deslizamentos em encostas na Serra do Mar - Brasil. Solos e Rochas, v. 12, n. 1, p. 27-36, 1989.

WU, T. H. Investigation of landslides on Prince of Wales Island. Geotechnical Engineering Report 5, Civil Engineering Department, Ohio State University, Columbus, Ohio, USA, 1976. 106 p.

WU, T. H.; MCOMBER, R. M.; ERB, R. T.; BEAL, P. E. Study of soil-root interaction. Journal of Geotechnical Engineering, v. 114, n. 12, p. 1351-1375, 1988.

WU, T. H. Slope stabilization. In: MORGAN, R. P. C.; RICKSON, R. J. (eds.). Slope Stabilization and Erosion Control: A Bioengineering Approach. London: E \& FN Spon, 1995. p. 233-282.

WU, T. H. Root reinforcement of soil: review of analytical models, test results, and applications to design. Canadian Geotechnical Journal, v. 50, n. 3, p. 259-274, 2013.

WU, T. H.; MCKINNELL, W. P.; SWANSTON, D. N. Strength of tree roots and landslides on Prince of Wales Island, Alaska. Canadian Geotechnical Journal, v. 16, n. 1, p. 19-33, 1979.

WU, T. H.; KOKESH, C. M.; TRENNER, B. R.; FOX, P. J. Use of live poles for stabilization of a shallow slope failure. Journal of Geotechnical and Geoenvironmental Engineering, v. 140, n. 10, p. 1-13, 2014.
ZHANG, C. B.; CHEN, L. H.; JIANG, J. Why fine roots are stronger than thicker roots: The role of cellulose and lignin in relation to slope stability. Geomorphology, v. 206, n. 1, p. 196-202, 2014. 